\title{
Do Companies' Characteristics Play Key Roles in the Level of their Environmental Disclosures?
}

\author{
Hafez Abdo and Ali Al-Drugi \\ Department of Accounting, Nottingham Business School, \\ Nottingham Trent University, Burton Street, Nottingham, NG1 4BU, UK
}

Received 2012-04-03, Revised 2012-07-04; Accepted 2012-07-10

\begin{abstract}
After reviewing the literature, we noticed that the vast majority of studies in the field of environmental accounting and disclosure have focused on developed countries such as Western Europe, America and Australia, while neglected developing countries. This study investigates the relationship between the level of environmental disclosure and company's characteristics. The researchers identified a number of characteristics that associate with companies' environmental disclosure, these are: Company's size, company's privatization, company's age and company's nationality. In the light of empirical results it is noticed that almost $100 \%$ of companies disclose some environmental information and they provide three types of environmental information good, neutral and bad news. In addition a significant positive association found between level of environmental disclosure and company's size, company's privatization and company's nationality. Therefore it provide further evidence which emphasize that these characteristics are important elements and have an impact on the level and value of environmental disclosure. On the other hand it was found that age of company is insignificant and negatively related to the level of environmental disclosure.
\end{abstract}

Keywords: Environmental Disclosures, Gas Industry, Oil Companies Operating

\section{INTRODUCTION}

Full disclosure is a characteristic of information quality in the accounting thought. In addition, it is the mainstream media for all information on corporate activities to those parties interested in such information. Considering the importance and magnitude of environmental costs which are increasing year on year, a pressing need has emerged to disclose those costs due to the impact it has on the effectiveness of decisions taken by users of financial statements and reports, especially in light of the fierce competition emanating from local and global companies. As such, investors have been made aware of that and started pressing for the urgent need to disclose environmental information in their published annual reports.

Through reviewing the literature, it has been noticed that the vast majority of studies in the field of environmental accounting and disclosure have focused on developed countries such as Western Europe, America and Australia, including even international studies which have also focused on these countries while neglected developing countries. According to some studies it is dangerous and wrong to apply results of these studies on developing countries (Tsang, 1998; Gao et al., 2005). Since environmental disclosure varies from one country to other due to economic, social, political and cultural differences, this results in differences in general and environmental disclosure in particular between different countries (Elnaby et al., 2003). Mashat (2005) examined disclosure of social responsibility in Libya; he recommended the need to study the disclosure of social activities individually especially the environmental disclosure, due to the lack of studies on environmental disclosure in Libya.

Therefore, the importance of this study emerges from the belief of many writers, including the researchers that the improvement and development of quality and quantity of corporate environmental disclosure does not only require studying current environmental disclosures, but it also requires studying and analysing the characteristics of companies and their possible influence on the environmental disclosure

Corresponding Author: Hafez Abdo, Department of Accounting, Nottingham Business School, Nottingham Trent University, Burton Street, Nottingham, NG1 4BU, UK 
practice. Also, this study comes at a time when Libya is being steered towards privatization, i.e., shifting from the public sector to the private sector, with all that follows such as the increase in the information demand from the categories using this information in particular investors considering that environmental information is of high importance to the current and potential investors in helping them to adopt sound decisions.

\subsection{Literature Review}

Since 1990, there has been a growing interest in environmental disclosure as one of the most important types of social disclosure (Islam et al., 2005). Environmental disclosure is one of the major components of social disclosure and contributes largely to meeting the needs of users of reports and financial statements by providing information that will assist them in assessing the efficiency of organisations when it comes to the use of economic resources and the extent to which they contribute to the fulfilment of social responsibility in terms of environmental protection and preservation of resources as well as sparing the community the risks of contamination (Akhtaruddin, 2005).

As a result of increasing concern for the environment and the disclosure of social and environmental activities in recent years, professional organizations, particularly investors, giving that environmental information will affect the decisions relating to the continuation of investments in companies which cause environmental pollution. There are many studies which focus on identifying company practice when disclosing environmental information, in order to identify the levels of disclosure in different countries. Such studies conclude that although many companies significantly increased their disclosure levels the amount and nature of information disclosed varies significantly across the countries (Gray et al., 2001). Along similar lines some studies in different countries were conducted in order to examine the link between environmental disclosures and some company-specific factors or characteristics, such as firm size, company age, company nationality and privatisation. Number of these studies agrees that there is a positive correlation between environmental disclosure and the size of the company see for example (Gray et al., 2001; Abreu et al., 2012). In other words, environmental disclosure increases considerably in large companies. In contrast, there is evidence that there is no positive correlation between environmental disclosure and the size of company see for example as (Akhtaruddin, 2005; Archambault and Archambault, 2003). In line with the view of these prior studies, but with another scope of social responsibility (Zubek, 2008) examined disclosure of Human Resource (HR) as one of the scope and activities of social responsibility in Libya stated that the size of companies does not appear to be significant to HR disclosure practices. He argues that the small companies appear to be more receptive to pressure groups in disclosing more HR information and the total amount of HR information disclosed by small companies is greater than that disclosed by meduim and large sized companies. With regard to the other determinants there are evidences found in some previous studies which consider company's nationality as key determinant of environmental disclosures. For example (Zarzeski, 1996; Saida, 2009), on the other hand, it was observed that the results of a number of prior studies indicated that foreign companies have a negligible effect on the environmental disclosure practices; (Moneva and Llena, 2000; Hossain et al., 2006). Furthermore, (Jangou et al., 2007) demonstrates noteworthy finding that more disclosure by Malaysian local companies as compared to their foreign counterparts.

Moreover (Cormier and Gordon, 2001; Wang et al., 2004) argue that there is significance lack between privatization and environmental disclose; in other words, public companies are more willing to disclose environmental information than private companies. On the other hand (Hassan et al., 2006; Uwalomwa, 2011) argue that there is a difference found in environmental disclosure between privet and public companies but this difference seems to be in favour of privet companies, therefore, they emphasise that company's privatization is an important element and has an impact on the level and value of environmental disclosure. In addition, there is evidence confirms that old companies are more likely to disclose social information (Zubek, 2008; Owusu-Ansah, 1998). However, (Akhtaruddin, 2005; Alsaeed, 2006) argue that age of company does not have a significant influence on the disclosure of social information.

Prior studies tried to test relationship between company's characteristics and environmental disclosure; they did not provide conclusive evidences for supporting these characteristics. In addition, the vast majority of studies have focused on developed countries while neglecting developing countries. Furthermore, it may be misleading to apply the results of western studies on developing countries, (Gao et al., 2005). This is because environmental disclosure varies from one country to another and from one community to another as a result of economic legal, social, political and cultural differences, which may impact accounting practice in general and accounting disclosure in particular (Belkaoui, 1983; Perera and Mathews, 1990). In addition to the above, several studies have recommended the need to focus research in the area of environmental disclosure in developing countries particularly in Libya where there is a gap in the accounting literature when considering environmental disclosure in developing countries. Also, 
there is still controversy surrounding the correlation between the influence of company's characteristics and environmental disclosure. The present study is motivated by the lack of research in developing countries, the Arab World and Libya in particular regarding environmental disclosure and the controversy surrounding the company's characteristics and their influence on this disclosure. In addition, this study conducted in oil and gas sector which is considered as one the most polluting of the industrial sectors to the environment as well as representing $70 \%$ of the proceeds of the industrial sector in GDP in Libya. This study will attempt to answer the following questions:

- Is there any environmental disclosure practice by oil companies operating in Libya? If so, what type of environmental information is being disclosed in the annual reports of those companies? And,

- Is there an association between characteristics of companies such as (company's size, privatization, company's age and company's nationality) and the level of their environmental disclosure?

\subsection{Methodology}

To answer the defined research questions, annual reports were used in this study as suitable documents for collecting information about environmental disclosures from 43 national and foreign oil and gas companies operating in Libya. Content analysis was used to provide a preliminary analysis for the quantity and nature of environmental disclosure practices in the Libyan oil and gas industry. According to (Neuendorf, 2002) content analysis technique is considered the fastest growing technique in quantitative research and has been used broadly in prior studies of social disclosure in general and environmental disclosure in particular e.g., (Gray et al., 2001; Freedman and Stagliano, 2008).

\subsection{Data Discussion and Analysis}

To answer the research questions non-parametric statistical and descriptive methods were used. In other words to identify the existence of environmental disclose disclosure and investigate the relationship between number of company's characteristics and environmental disclosure, the descriptive statistics was used to identify the type of environmental information is being disclosed in the annual reports of oil and gas companies? In addition, the Mann-Whitney test was used to test the difference between local and foreign companies. Finally the researcher used the liner correlation coefficient $r$ to measure the strength and direction of the relationship between company's characteristics and environmental disclosure.

\subsection{Level of Corporate Environmental Disclosure According to Kind of Companies (Local and Foreign Companies)}

The mean value of environmental disclosure practice, minimum and maximum of words of environmental disclosure for twenty four local and foreign companies operating in the oil and gas industry in Libya over the 8 year period from 2002-2009 is presented in Table 1. The trend in environmental disclosure in general indicates that almost $100 \%$ of companies provide some environmental information, with it steadily increasing in average value throughout the period. The mean row indicates that the mean value of environmental disclosure by local companies rose from 15.67 words in 2002-191.7 words in 2009. The minimum and maximum values are shown, suggesting that the minimum number of words is rising from 7-158 and the maximum from 23-229 words from 2002-2009 respectively, while the mean value of environmental disclosure by foreign companies rose from 102.33 words in 2002-297 words in 2009 with minimum words increasing from 93-193 and maximum from 113-400 respectively. Consequently the range between the minimum and maximum of words was high and increasing for all years.

Table 1 shows that the value of the mean environmental disclosure of foreign companies is higher compared to the value of the mean environmental disclosure of local companies. Therefore it can be noted that there is a significant difference in environmental disclosure between local and foreign companies over the period, particularly between 2002 and 2004. While $13.28,12.47$ and $14.28 \%$ of environmental disclosure in 2002-2004 respectively was reported by local companies 86.7287 .53 and $85.72 \%$ was reported by foreign companies. However these differences were reduced in 2005-2009; while the percentages of environmental disclosure reported by foreign companies during these years were 74.37, 62.81, 58.98, 61.94 and $60.77 \%$ respectively. The percentages of environmental disclosure reported by local companies during the same years were $25.63,37.19,41.02,38.06$ and $39.23 \%$. The reason for the reduction of the differences between local and foreign companies regarding environmental disclosure is the increase in environmental disclosure by local companies. This increase may be ascribed to several reasons most importantly, that the increase of environmental legislation in Libya especially environmental law no, 13 of 2003 that leads to more attention to environmental disclosure. Although, in practice there is no real obligation for companies to disclose their environmental activities, local companies 
especially that operating in oil and gas sector tend to comply with the laws may be because environmental disclosure will help them to give an impression of the extent of their commitment to environmental laws.

Moreover, Table 1 demonstrates that the ratio of mean total environmental disclosure is not quite $37 \%$ in local companies while it is more than $63 \%$ in foreign companies. In an attempt to justify this difference, the researchers ascribe this difference for number of reasons, social and environmental disclosure may help a company to improve its image and promote its goodwill before the public opinion, since members of the community usually believe that foreign companies come to steal the wealth of their country. In addition companies may be resort to the disclosure of social and environmental information in an attempt to improve their reputation and erase the negative effects caused by environmental accidents especially for companies with a reputation which may have been damaged as a result of an accident or an environmental disaster such spill large quantities of crude oil by Exxon company in coasts of Alaska in 1989 and BP company in the Gulf of Mexico 2010, in addition Union Carbide's chemical leak in Bhopal, India in 1984. Also The Company may disclose social and environmental performance in order to strengthen competitiveness and distinctiveness of the company for example: many companies believe that social and environmental disclosure will give them the priority in terms of new contracts for oil exploration in the future.

Based on comparing the mean and the percentages of environmental disclosure for each year, it is clear that there is apparent difference in environmental disclosure practice in the two groups of companies, which seems to be in favour of foreign companies.

Table 1. Descriptive statistics for environmental disclosure practice by local and foreign companies in Libya

\begin{tabular}{|c|c|c|c|c|c|c|c|c|c|c|}
\hline \multirow[b]{2}{*}{ Company } & \multirow[b]{2}{*}{ Statistics } & \multicolumn{8}{|l|}{ Years } & \multirow[b]{2}{*}{ Overall mean } \\
\hline & & 2002 & 2003 & 2004 & 2005 & 2006 & 2007 & 2008 & 2009 & \\
\hline \multirow[t]{7}{*}{ Local } & $\mathrm{n}$ & 3.00 & 5.0000 & 7.000 & 6.00 & 9.00 & 8.000 & 10.00 & 10.000 & \\
\hline & Mean & 150.67 & 17.0000 & 27.430 & 60.83 & 99.00 & 143.600 & 156.60 & 191.700 & 605.2 \\
\hline & $\%$ & 13.28 & 12.4700 & 14.280 & 25.63 & 37.19 & 41.020 & 38.06 & 39.230 & 36.6 \\
\hline & SD & 8.08 & 3.8620 & 10.876 & 22.28 & 28.62 & 23.469 & 32.06 & 25.337 & 172.8 \\
\hline & Minimum & 7.00 & 14.0000 & 17.000 & 24.00 & 54.00 & 112.000 & 90.00 & 158.000 & 225.0 \\
\hline & Maximum & 23.00 & 23.0000 & 43.000 & 92.00 & 143.00 & 176.000 & 191.00 & 229.000 & 783.0 \\
\hline & $\mathrm{n}$ & 3.00 & 3.0000 & 3.000 & 6.00 & 11.00 & 14.000 & 14.00 & 14.000 & \\
\hline \multirow{5}{*}{ Foreign } & Mean & 102.33 & 119.3300 & 164.670 & 176.50 & 167.18 & 206.400 & 254.86 & 297.000 & 1048.4 \\
\hline & $\%$ & 86.72 & 87.5300 & 85.720 & 74.37 & 62.81 & 58.980 & 61.94 & 60.770 & 63.4 \\
\hline & SD & 10.06 & 14.2945 & 14.360 & 27.99 & 59.45 & 53.392 & 59.09 & 59.660 & 364.6 \\
\hline & Minimum & 93.00 & 107.0000 & 154.000 & 132.00 & 95.00 & 134.000 & 167.00 & 192.000 & 594.0 \\
\hline & Maximum & 113.00 & 135.0000 & 181.000 & 214.00 & 272.00 & 310.000 & 346.00 & 400.000 & 1500.0 \\
\hline
\end{tabular}

Table 2. Correlations between company's privatization and environmental disclosure

\begin{tabular}{llcc}
\hline & & Nationality of Company & Environmental disclosure \\
\hline Nationality of company & Pearson Correlation & 1.000 & $0.604^{* *}$ \\
& Sig. (2-tailed) & $24.000^{* *}$ & 0.002 \\
& N & $0.604^{* *}$ & 1.000 \\
& Pearson Correlation & 0.002 & 24.000 \\
& Sig. (2-tailed) & 24.000 & \\
\hline
\end{tabular}

**: Correlation is significant at the 0.01 level.

Table 3. Descriptive statistics for the type of corporate environmental disclosure by local and foreign companies

\begin{tabular}{|c|c|c|c|c|c|c|c|c|c|c|c|}
\hline \multirow[b]{2}{*}{ Company } & \multirow[b]{2}{*}{ Kind of disclosure } & \multicolumn{8}{|l|}{ Years } & \multirow[b]{2}{*}{ Total } & \multirow[b]{2}{*}{$(\%)$} \\
\hline & & 2002 & 2003 & 2004 & 2005 & 2006 & 2007 & 2008 & 2009 & & \\
\hline \multirow{5}{*}{ Local } & Number of reports & 3.00 & 5.00 & 7.0 & 6.0 & 9.0 & 8.0 & 10.0 & 10.0 & & \\
\hline & Bad news & 2.00 & 22.00 & 56.0 & 13.8 & 24.5 & 37.3 & 44.6 & 53.6 & 183.6 & 26.0 \\
\hline & Neutral news & 0.00 & 1.80 & 3.4 & 16.2 & 25.8 & 42.4 & 42.1 & 57.2 & 188.9 & 26.5 \\
\hline & Good news & 13.70 & 13.00 & 18.4 & 30.8 & 48.7 & 64.0 & 69.9 & 80.9 & 339.4 & 47.5 \\
\hline & Total & 15.70 & 17.00 & 27.4 & 60.8 & 99.0 & 143.7 & 156.6 & 191.7 & 711.9 & 100.0 \\
\hline \multirow[t]{5}{*}{ Foreign } & Number of reports & 3.00 & 3.00 & 3.0 & 6.0 & 11.0 & 14.0 & 14.0 & 14.0 & & \\
\hline & Bad news & 18.30 & 17.30 & 23.7 & 28.5 & 26.8 & 38.2 & 46.1 & 57.2 & 256.1 & 17.0 \\
\hline & Neutral news & 31.00 & 38.30 & 59.7 & 58.7 & 52.4 & 65.3 & 80.0 & 95.1 & 480.5 & 32.0 \\
\hline & Good news & 53.00 & 63.70 & 81.3 & 89.3 & 88.0 & 102.9 & 128.7 & 144.7 & 751.6 & 51.0 \\
\hline & Total & 102.30 & 119.30 & 164.7 & 176.5 & 167.2 & 206.4 & 254.8 & 279.0 & 1488.2 & 100.0 \\
\hline
\end{tabular}

$\%=$ the percentage of total of disclosure 
To identify whether or not the difference between the amounts of environmental disclosure practice between local and foreign oil and gas companies operating in Libya is a significant, the Mann-Whitney test was used. The result indicates that there is in fact a significant difference in the amounts of environmental disclosure between local and foreign companies at the levels $(Z$ - statistic $=-2.46, p$-value $=0.014)$, because the calculated $Z$ value is below -1.96 and the $p$-value is less than 0.05 this indicate that the difference between the amounts of environmental disclosure practice between local and foreign oil and gas companies operating in Libya is a statistically significant. Thus the environmental disclosure is influenced by the company's nationality.

For further confirm of the above results the liner correlation coefficient $r$ was used. As can be seen from Table 2, the correlation coefficient of .604 indicates that the relationship between the two variables, company's nationality and environmental disclosure is very strong. So a positive correlation was found to exist between company's nationalities and disclose of environmental information. That means company's nationality is important factor and has an impact on the level of environmental information:

$\mathrm{H}_{\mathrm{o}}$ : There is no significant difference in environmental disclosure practice between local and foreign companies.

And the alternative hypothesis is accepted:

$\mathrm{H}_{1}$ : There is a significant difference in environmental disclosure practice between local and foreign companies.

According to the empirical findings provided above; it was observed that there is a significant difference in the level of environmental disclosure between domestic and foreign companies and this difference seems to be in favour of foreign companies. Thereby finding supports arguments that there is relationship between company's nationality and environmental disclosure and it provide further evidence which emphasize that the idea of this characteristic is important element and has an impact on the level and volume of environmental disclosure.

\subsection{The Type of Corporate Environmental Disclosure}

Environmental disclosure news that appeared in the reports of local and foreign companies are summarized and reported in Table 3. It illustrates the descriptive statistics for three categories: good, neutral and bad environmental disclosure, by companies operating in the oil and gas sector in Libya.

As can be seen from Table 3 the average number of words of disclosure for local companies is 183.6 for bad news, 188.9 for neutral news and 339.4 for good news, while the average number of total disclosed words of foreign companies is 256.1 for bad news, 480.5 for neutral news and 751.6 for good news. Based on comparing the sort of environmental disclosure for each year, as Table 3 demonstrates, it can be noticed that more attention was paid to the good news and the results show that nearly half of the information disclosed was good news, whether in local or foreign companies.

Table 3 also summarizes that the proportion of bad news in total environmental disclosure is nearly $26 \%$ in local companies while it is $17 \%$ in foreign companies. This means that disclosure of bad news is more dominant in local companies compared to foreign companies. The high average number of total disclosures in bad news in local companies may be ascribed to all local companies being public companies that do not have shareholders or shares traded in the stock market, so the kind of disclosure, whether good, neutral or bad does not have much effect on their share price and they do not seek so much to improve their reputation compared with the private companies.

This is consistent with the findings in the accounting literature that the major reason for companies to disclose their environment activities is to maintain their reputation and appease investors and other businesses, especially at a time of emergence of what is known as the "ethical investor" who prefers to invest in companies whose activities do not cause damage to the environment (Stevens 1991; Deegan and Rankin 1997; Barth and McNichols 1994).

Therefore, the level and kind of environmental disclosure and the commitment of companies to preserve the environment can affect the decision of shareholders to continue investing in the company, since investors prefer to invest in companies that engage in disclosing their environmental practices and are not causing damage to the Environment. Thus the private companies seek to improve their image and reputation before the general public by focusing more on disclosure of good and neutral news rather than bad news.

\subsection{Level of Corporate Environmental Disclosure According to the Size of Company (Small, Medium and Large Size)}

The researchers have chosen the number of employees to measure the size of company; they did so for number of reasons. First it is very difficult to use other way such as value of total assets, the market value of equity or capital employed because the difficult to obtain the information related these ways under the pretext of confidentiality. In contrast the information about the employees can be obtained. This tool has used by many studies such as (Gray et al., 2001 GonzalezBenito and Gonzalez-Benito 2006; Halme and Morten 
1997). As can be seen from Table 4 the analysis indicates that large companies disclose more environmental information than other kinds of companies (medium and small size) with the average number of total disclosures 1151.3, 721.9 and 502 words respectively. Also Table 4 demonstrates that the average amount of environmental disclosure increased year an year in all groups of companies, large, medium and small. The highest proportion of mean total environmental disclosure was nearly $27 \%$ in small companies in 2007 while it was $33.3 \%$ in 2009 in medium companies; In contrast the highest ratio of mean total environmental disclosure was almost $80 \%$ in the large companies in 2002. In addition, the overall rate of environmental disclosure was nearly $50 \%$ of large companies, compared to 30.4 and $21.1 \%$ of medium and small companies respectively.

Based on comparing the mean and the percentages of environmental disclosure for each year, it is clear that there is an apparent difference in environmental disclosure practice in the three groups of companies Large, medium and small, which seems to be in favour of large companies. Depending on the above analysis there is a significant difference in the level of environmental disclosure between Large, medium and small companies and this difference seems to be in favor of Large and medium companies respectively. Thus, the investigation suggests that there is an association between company's size and environmental disclosure. However, the analysis confirms that company's size is a significant factor for environmental disclosure. For further analysis the MannWhitney test was used. The result between large and small companies at the level was $(Z$-statistic $=-3.317$, p- value $=0.001)$, while between Large and medium companies it was at the level (Z-statistic $=-2.672$, pvalue $=0.008$ ) and between medium and small companies it was at the level (Z-statistic $=-2.646$, pvalue $=0.008)$. The calculated $Z$ values for all sizes of company are below -1.96 and the p-values are less than 0.05, which mean the difference between Large, medium and small companies are a statistically significant.

For further confirm the above results; the liner correlation coefficient $r$ was conducted to assess the relationship between company's age and the level of environmental disclosure. Table 6 illustrates that there is a positive correlation between size of company and environmental disclosure in the annual reports of oil and gas companies operating in Libya.

To measure the strength and direction of the relationship between large, medium and small companies and environmental disclosure is significant or no, the liner correlation coefficient $r$ was conducted. As can be seen from Table 5 the correlation coefficient of 0.753 indicates that there is significantly and positively associated between the two variables, size of company and environmental disclosure. This means companies that are larger in size; tend to have possibility higher levels of environmental disclosure.

Based on the analysis and findings above, there is difference in environmental disclosure between Large, medium and small companies is a statistically significant and this difference seems to be in favor of Large company. Which mean that small companies had lower environmental disclosures than large companies?

Table 4. Descriptive statistics of environmental disclosure by small, medium and large size companies

\begin{tabular}{|c|c|c|c|c|c|c|c|c|c|c|}
\hline \multirow[b]{2}{*}{ Company } & \multirow[b]{2}{*}{ Statistics } & \multicolumn{8}{|l|}{ Years } & \multirow[b]{2}{*}{ Overall } \\
\hline & & 2002 & 2003 & 2004 & 2005 & 2006 & 2007 & 2008 & 2009 & \\
\hline \multirow[t]{6}{*}{ Small } & $\mathrm{n}$ & 0.0 & 1.0 & 2.0 & 2.0 & 5.0 & 4.0 & 6.0 & 6.0 & \\
\hline & Mean & 0.0 & 14.0 & 21.0 & 41.5 & 82.0 & 137.8 & 137.8 & 192.3 & 502.0 \\
\hline & $\%$ & 0.0 & 14.2 & 13.0 & 16.6 & 22.1 & 26.8 & 25.0 & 26.4 & 21.1 \\
\hline & SD & 0.0 & & 1.4 & 24.7 & 19.6 & 21.4 & 44.4 & 36.7 & 155.0 \\
\hline & Minimum & 0.0 & 14.0 & 20.0 & 24.0 & 54.0 & 112.0 & 90.0 & 158.0 & 255.0 \\
\hline & Maximum & 0.0 & 14.0 & 22.0 & 59.0 & 100.0 & 164.0 & 220.0 & 261.0 & 645.0 \\
\hline \multirow[t]{6}{*}{ Medium } & $\mathrm{n}$ & 2.0 & 1.0 & 3.0 & 1.0 & 5.0 & 7.0 & 7.0 & 7.0 & \\
\hline & Mean & 20.0 & 16.0 & 30.0 & 67.0 & 113.6 & 165.1 & 203.4 & 241.6 & 721.9 \\
\hline & $\%$ & 20.3 & 16.2 & 18.5 & 26.8 & 30.6 & 32.1 & 33.3 & 33.2 & 30.4 \\
\hline & SD & 4.2 & & 11.3 & & 25.8 & 29.6 & 41.7 & 53.3 & 120.9 \\
\hline & Minimum & 17.0 & 16.0 & 17.0 & 67.0 & 91.0 & 133.0 & 149.0 & 162.0 & 597.0 \\
\hline & Maximum & 23.0 & 16.0 & 37.0 & 67.0 & 149.0 & 206.0 & 268.0 & 318.0 & 895.0 \\
\hline \multirow[t]{6}{*}{ Large } & $\mathrm{n}$ & 4.0 & 6.0 & 5.0 & 9.0 & 10.0 & 11.0 & 11.0 & 11.0 & \\
\hline & Mean & 78.5 & 68.8 & 110.8 & 141.6 & 175.2 & 212.0 & 254.0 & 293.6 & 1151.3 \\
\hline & $\%$ & 79.7 & 68.8 & 110.8 & 141.6 & 175.2 & 212.0 & 254.0 & 293.6 & 1151.3 \\
\hline & SD & 48.4 & 56.1 & 75.0 & 57.7 & 56.0 & 59.2 & 70.5 & 74.2 & 331.6 \\
\hline & Minimum & 7.0 & 14.0 & 17.0 & 54.0 & 92.0 & 116.0 & 150.0 & 195.0 & 686.0 \\
\hline & Maximum & 113.0 & 135.0 & 181.0 & 214.0 & 272.0 & 310.0 & 346.0 & 400.0 & 1500.0 \\
\hline
\end{tabular}

$\mathrm{N}=$ number of annual reports $\%=$ the percentage of disclosure $\quad \mathrm{SD}=$ Standard deviation 
Table 5. Correlations between size of company and environmental disclosure

\begin{tabular}{llcc}
\hline & & Size of company & Environmental disclosure \\
\hline Size of company & Pearson Correlation & 1.000 & $0.753^{* *}$ \\
& Sig. (2-tailed) & & 0.000 \\
& $\mathrm{~N}$ & 24.000 & 24.000 \\
Environmental disclosure & Pearson Correlation & $0.753^{* *}$ & 1.000 \\
& Sig. (2-tailed) & 0.000 & 24.000 \\
\hline
\end{tabular}

**: Correlation is significant at the 0.01 level

Table 6. Descriptive statistics for environmental disclosure practice by private and public corporations

\begin{tabular}{|c|c|c|c|c|c|c|c|c|c|c|}
\hline \multirow[b]{2}{*}{ Company } & \multirow[b]{2}{*}{ Statistics } & \multicolumn{9}{|l|}{ Years } \\
\hline & & 2002 & 2003 & 2004 & 2005 & 2006 & 2007 & 2008 & 2009 & Overall \\
\hline \multirow[t]{6}{*}{ Public } & $\mathrm{n}$ & 3.00 & 5.0000 & 7.0000 & 6.00 & 9.00 & 8.0000 & 10.00 & 10.000 & \\
\hline & Mean & 15.67 & 17.0000 & 27.4300 & 60.83 & 99.00 & 143.6000 & 156.60 & 191.700 & 605.2 \\
\hline & $\%$ & 13.28 & 12.4700 & 14.2800 & 25.63 & 37.19 & 41.0200 & 38.06 & 39.230 & 36.6 \\
\hline & SD & 8.08 & 3.8620 & 10.8759 & 22.28 & 28.62 & 23.4693 & 32.06 & 25.337 & 172.8 \\
\hline & Minimum & 7.00 & 14.0000 & 17.0000 & 24.00 & 54.00 & 112.0000 & 90.00 & 158.000 & 225.0 \\
\hline & Maximum & 23.00 & 23.0000 & 43.0000 & 92.00 & 143.00 & 176.0000 & 191.00 & 229.000 & 783.0 \\
\hline \multirow[t]{6}{*}{ Private } & $\mathrm{n}$ & 3.00 & 3.0000 & 3.0000 & 6.00 & 11.00 & 14.0000 & 14.00 & 14.000 & \\
\hline & Mean & 102.33 & 119.3300 & 164.6700 & 176.50 & 167.18 & 206.4000 & 254.90 & 297.000 & 1048.4 \\
\hline & $\%$ & 86.72 & 87.5300 & 85.7200 & 74.37 & 62.81 & 58.9800 & 61.94 & 60.770 & 63.4 \\
\hline & SD & 10.06 & 14.2945 & 14.3600 & 27.99 & 59.45 & 53.3924 & 59.09 & 59.660 & 364.6 \\
\hline & Minimum & 93.00 & 107.0000 & 154.0000 & 132.00 & 95.00 & 134.0000 & 167.00 & 192.000 & 594.0 \\
\hline & Maximum & 113.00 & 125.0000 & 181.0000 & 214.00 & 272.00 & 310.0000 & 346.00 & 400.000 & 1500.0 \\
\hline
\end{tabular}

$\mathrm{n}=$ number of annual reports $\quad \%=$ the percentage of disclosure $\quad \mathrm{SD}=$ standard deviation

A number of reasons have been advanced in the literature in an attempt to justify relationship between company's size and the level of environmental disclosure, Wallace pointed out that size is a function of growth and the growth of a firm invariably results in a greater need for external capital and consequently a greater need for more comprehensive information. In addition, (McKinnon and Dalimunthe, 1993) suggest that although large and small companies will collect information for internal planning and control purposes however, large companies may be need more analyst and disclosure of information than small companies to use as a tool for planning, monitoring and evaluation of performance therefore may be they disclose more important information than small companies.

Moreover, (Cooke, 1989; 1991) pointed out several reasons for expecting a positive association between the size of company and the extent of disclosure he argues that "larger companies are likely to be entities of economic significance. So, that may be greater demands on them to provide information for customers, suppliers and analysts and governments as well as the general public". Another reason for increased disclosure by large companies is that such businesses are likely to be more complex. They are more likely to be multiproduct operate in a number of geographical areas including overseas. These additional complexities require efficient management information systems to meet the needs for managerial control and meet the needs of financiers. Along similar lines (Adams, 2002) shows that large companies usually gather the information for social and environmental disclosures more than one employee, however small company usually has a one person responsible for the whole process. This fact may be influences the level and amount of environmental disclosure. Finally, (Marston and Shrives, 1991) proposed that smaller corporations are more likely to feel that full disclosure of information could endanger their competitive position. For these reasons, it is rather that a large company is more likely to have underlying reasons for increased disclosure than a small company.

To sum up, the researcher may be able to ascribe this difference to some of reasons for instance larger companies usually have more shareholders than small companies who might be concerned with social programmers, some studies argue that many investors have started to invest in companies whose activities do not harm the environment and have started pressing for the urgent need to disclose environmental information in their published annual reports so, social and environmental disclosure helps the company to meet the pressures of its shareholders. Moreover, costs of providing this type of social and environmental information may far exceed the desired outcomes so; larger companies supposed have more resources and expertise to produce more and meet these financial requirements. 


\subsection{Level of Corporate Environmental Disclosure According to Company's Privatization (Private and Public Corporations)}

Information related to the environmental disclosure practice, which appeared in the annual reports, of public and private companies operating in the oil and gas industry in Libya over the 8 year period, from 20022009, is presented in Table 6. Overall the results indicate that all companies, whether public or private corporations, made some environmental disclosure in all years. In more details, the mean values of environmental disclosure are shown in Table 6; the mean number of words of disclosure by the public companies rose from 15.67 in $2002-191.7$ in 2009, while the mean value of environmental disclosure by foreign companies raised from 102.33 words in 2002-297 words in 2009. Thus it steadily increased in average value over all the period, this increase may be due to the increase of environmental legislation in Libya especially environmental law no, 13 of 2003 that leads to more attention to environmental disclosure.

Based on the above and the rest of the information related to the environmental disclosure practice between public and private companies, which appears in Table 6, for each year, it is clear that more attention was paid to environmental disclosure by private companies than public companies, who are likely to include more environment information in their annual reports in order to enhance their reputation and image in the market.

The failure to disclose environmental performance and programs for improvement and continuous development in this field can lead to negative impacts on the company's reputation and competitive position in the capital market, thus, companies use disclosure as a means of achieving and maintaining the competitive advantage in its area of activity (Ince, 1998; Solomon and Lewis 2002). This may be can result in an increased market value of their shares based on the principle that investors prefer to invest in companies that disclose and show interest in environmental performance. Therefore, private companies disclose information to a greater extent than public companies.

In conclusion, there is difference in the level of environmental disclosure between public and private companies. This difference may be ascribed to pressure imposed on private companies by environmental organizations and by investors. It is argued in many studies that the level of environmental disclosure and the commitment of companies to preserve the environment may affect the decision of shareholders to continue investing in the company. Since investors prefer to invest in companies that engage in disclosing their environmental practices and are not causing damage to the environment (Deegan and Rankin 1997; Ingram
1978; Medley, 1997). Therefore private companies are more concerned to improve their image and reputation in the eyes of the public opinion than public companies, which do not have shareholders or share in the stocks traded on market. Other possible explanations could be that private companies concern with environmental disclosure more than public companies because some committees with some kind of a connection such as the Securities and Exchange Commission (SEC), obliges companies dealing in the stock market to provide a set minimum of information for investors (Stanko et al., 2006; Beets and Souther 1999).

In conclusion, there is difference in the level of environmental disclosure between public and private companies. This difference may be ascribed to pressure imposed on private companies by environmental organizations and by investors.

For further analysis the Mann-Whitney test was carried out to understand whether or not this different is a significant. The results reveal that there is significant difference in the amounts of environmental disclosure between public and private companies at the level (Zstatistic $=-2.460, \mathrm{P}$-value $=0.014)$, because the calculated $\mathrm{Z}$ value is below -1.96 and the p-value is less than 0.05 . Based on this investigation, the different in environmental disclosure between private and public companies is a statistically significant.

Moreover, to the possible association of local and private Company with environmental disclosure, the liner correlation coefficient $r$ was used to examine the strength and direction of the relationship between these two variables. As can be seen from Table 7, the correlation coefficient of 0.604 indicates that the relationship between the two variables, company's privatization and environmental disclosure, is very strong. There is significant difference between private and public companies regarding disclose of environmental information. So it is found that private companies are more likely than public companies to disclose environmental information in their annual reports.

The findings therefore provide further evidence which emphasize that the idea of company's privatization is an important element and has an impact on the level and volume of environmental disclosure. The null hypothesis, therefore, is rejected:

$\mathrm{H}_{\mathrm{o}}$ : There is no significant difference in the amounts of environmental disclosure practice between public and private companies.

And the alternative hypothesis is accepted:

$\mathrm{H}_{1}$ : There is a significant difference in the amounts of environmental disclosure practice between public and private companies. 


\subsection{Level of Environmental Disclosure According to Age of Company (Old and New Company}

Table 8 indicates that there is a convergence in the rate of environmental disclosure over the period 20022009 between old and new companies. The maximum number of words was 374 and the minimum was 158 by old companies while the maximum and minimum number of word disclosed by new companies was 400 and 170 respectively.

Based on this investigation, we can state that there is no difference in environmental disclosure between old and new companies. Possible explanations could be whether old or new companies want to meet the pressures of their shareholders and pressure groups as a whole. Also may be as obligation by requirements of some Securities and Exchange Commission (SEC) which ask companies to disclose the minimum of information for investors. These companies may do so in order to strengthen competitiveness and distinctiveness of the company.

To make sure that this difference is significant or not, the Mann-Whitney test was used. The analysis reveals that there is no significant difference in the amounts of environmental disclosure between old and new companies at the level $(Z$ - statistic $=-0.600$, p-value $=0.548)$, this is because the calculated $Z$; value is between -1.96 and +1.96 and $p$-value larger than 0.05 .
In addition, to confirm the above results, the liner correlation coefficient $r$ was conducted to assess the relationship between company's age and the level of environmental disclosure, as can be seen from Table 9, the correlation coefficient of -0.093 indicates that there is a relatively strong negative relationship between the two variables.

Therefore results find no positive significant support for the relationship between age of company and the level of environmental disclosure, which inducts that company's age is an insignificant factor for environmental disclosure. The null hypothesis therefore is accepted.

$\mathbf{H}_{\mathbf{0}}$ : There is no significant difference in environmental disclosure practice between old and new companies.

And the alternative hypothesis is rejected.

$\mathbf{H}_{1}$ : There is a significant difference in environmental disclosure practice between local and foreign companies.

Based on the empirical findings provided above; it was observed that the results did not support the hypothesis that old companies provide more environmental information than new companies. In other words, the investigation indicated that age of company has a negligible effect on the environmental disclosure practices.

Table 7. Correlations between company's privatization and environmental disclosure

\begin{tabular}{llcc}
\hline & & Privatization & Environmental disclosure \\
\hline Privatization & Pearson correlation & 1.000 & $.604^{* *}$ \\
& Sig. (2-tailed) & & 0.002 \\
& $\mathrm{~N}$ & 24.000 & 24.000 \\
Environmental disclosure & Pearson correlation & $.604^{* *}$ & 1.000 \\
& Sig. (2-tailed) & 0.002 & 24.000 \\
\hline
\end{tabular}

**: Correlation is significant at the 0.01 level

Table 8. Descriptive statistics for environmental disclosure practice by old and new companies

\begin{tabular}{|c|c|c|c|c|c|c|c|c|c|c|}
\hline \multirow[b]{2}{*}{ Company } & \multirow[b]{2}{*}{ Statistics } & \multicolumn{8}{|c|}{ Years } & \multirow[b]{2}{*}{ Overall } \\
\hline & & 2002 & 2003 & 2004 & 2005 & 2006 & 2007 & 2008 & 2009 & \\
\hline \multirow[t]{6}{*}{ Old } & $\mathrm{n}$ & 6.0 & 8.0 & 10.0 & 9.0 & 14.0 & 16.0 & 18.0 & 18.0 & \\
\hline & Mean & 59.0 & 55.4 & 68.6 & 131.0 & 136.9 & 185.9 & 215.4 & 256.4 & 883.1 \\
\hline & $\%$ & 100.0 & 100.0 & 100.0 & 61.6 & 50.2 & 51.1 & 50.7 & 51.4 & 52.2 \\
\hline & SD & 48.2 & 53.6 & 67.2 & 60.9 & 54.8 & 48.2 & 67.4 & 70.0 & 379.7 \\
\hline & Minimum & 7.0 & 14.0 & 17.0 & 59.0 & 54.0 & 116.0 & 90.0 & 158.0 & 225.0 \\
\hline & Maximum & 113.0 & 135.0 & 181.0 & 214.0 & 131.0 & 287.0 & 340.0 & 374.0 & 1500.0 \\
\hline \multirow[t]{6}{*}{ New } & $\mathrm{n}$ & 0.0 & 0.0 & 0.0 & 3.0 & 6.0 & 6.0 & 6.0 & 6.0 & \\
\hline & Mean & 0.0 & 0.0 & 0.0 & 81.7 & 135.7 & 177.3 & 209.3 & 242.5 & 805.7 \\
\hline & $\%$ & 0.0 & 0.0 & 0.0 & 38.4 & 49.8 & 48.9 & 49.3 & 48.6 & 47.8 \\
\hline & SD & 0.0 & 0.0 & 0.0 & 75.4 & 71.9 & 72.3 & 81.9 & 84.7 & 364.7 \\
\hline & Minimum & 0.0 & 0.0 & 0.0 & 24.0 & 70.0 & 112.0 & 124.0 & 170.0 & 500.0 \\
\hline & Maximum & 0.0 & 0.0 & 0.0 & 167.0 & 272.0 & 310.0 & 346.0 & 400.0 & 1495.0 \\
\hline
\end{tabular}

$\mathrm{n}=$ number of annual reports $\quad \%=$ the percentage of disclosure $\quad \mathrm{SD}=$ standard deviation 
Table 9. The Correlations between Age of company and environmental disclosure

\begin{tabular}{llcc}
\hline & & Age of company & Environmental disclosure \\
\hline Age of company & Pearson Correlation & 1.000 & -0.093 \\
& Sig. (2-tailed) & & 0.667 \\
Environmental disclosure & N & 24.000 & 24.000 \\
& Pearson Correlation & -0.093 & 1.000 \\
& Sig. (2-tailed) & 0.667 & 24.000 \\
\hline
\end{tabular}

\section{CONCLUSION}

This study investigates the relationship with regard to the level of environmental disclosure and company's characteristics, studying and analyzing environmental disclosure practices by local and foreign oil and gas oil companies operating in Libya and identifying the association between these characteristics are the main incentive to conduct this study. In the light of empirical results it can be noticed that almost $100 \%$ companies provide some environmental information and they disclose three types of environmental information good, neutral and bad news. However, more attention was paid to disclosure of good news, whether in local or foreign companies. On the other hand the proportion of total disclosure of bad news is high in local companies compared to foreign companies.

According to the empirical findings provided above; it is observed that there is a significant difference in the level of environmental disclosure between domestic and foreign companies and this difference seems to be in favour of foreign companies. Thereby finding supports arguments that there is relationship between company's nationality and environmental disclosure. In addition the analysis and findings above, confirm that there is difference in environmental disclosure between Large, medium and small companies is a statistically significant and this difference seems to be in favor of Large Company. Moreover, there is a meaningful different in environmental disclosure practice between private and public corporations operating in the oil and gas sector in Libya, which seems to be in favour of private companies. Therefore, a significant positive association found between level of environmental disclosure and company's size, company's privatization and company's nationality. Therefore it provide further evidence which emphasize that the idea of these characteristics are important elements and have an impact on the level and value of environmental disclosure. On the other hand only age of company does not have a statistically significant effect in the amount and level of environmental disclosure. Thus, the investigation did not support the hypothesis that old companies are likely to disclose more information in their annual reports than new companies.

\section{REFERENCES}

Abreu, M.C.S.D., F.D. Castro, F.D.A. Soares and J.C.L.D.S. Filho, 2012. A comparative understanding of corporate social responsibility of textile firms in Brazil and China. J. Cleaner Prod., 20: 119-126. DOI: 10.1016/j.jclepro.2011.08.010

Adams, C.A., 2002. Internal organisational factors influencing corporate social and ethical reporting: Beyond current theorising. Accou. Auditing Account. J., 15: 223-250. DOI: 10.1108/09513570210418905

Akhtaruddin, M., 2005. Corporate mandatory disclosure practices in Bangladesh. Int. J. Account., 40: 399422. DOI: 10.1016/j.intacc.2005.09.007

Alsaeed, K., 2006. The association between firm-specific characteristics and disclosure: The case of Saudi Arabia. Manage. Auditing J., 21: 476-496. DOI: 10.1108/02686900610667256

Archambault, J.J. and M.E. Archambault, 2003. A multinational test of determinants of corporate disclosure. Int. J. Account., 38: 173-194. DOI: 10.1016/S0020-7063(03)00021-9

Barth, M. and M. Mcnichols, 1994. Estimation and market valuation of environmental liabilities relating to superfund sites. J. Account. Res., 32: 177-209.

Beets, S.D. and C.C. Souther, 1999. Corporate environmental reports: The need for standards and an environmental assurance service. Account. Horizons, 13: 129-145. DOI: 10.2308/acch.1999.13.2.129

Belkaoui, A., 1983. Economic, political and civil indicators and reporting and disclosure adequacy: Empirical investigation. J. Account. Public Policy, 2: 207-219.

Cooke, E., 1991. An assessment of voluntary disclosure in the annual reports of Japanese corporations. Int. J. Account. Educ. Res., 26: 174-189.

Cooke, T.E., 1989. Disclosure in the corporate annual reports of Swedish companies. Account. Bus. Res., 19: 113-124. DOI: 10.1080/00014788.1989.9728841

Cormier, D. and I.M. Gordon, 2001. An examination of social and environmental reporting strategies. Account. Auditing Account. J., 14: 587-617. DOI: 10.1108/EUM0000000006264 
Deegan, C. and M. Rankin, 1997. The materiality of environmental information to users of annual reports. Account. Auditing Account. J., 10: 562-583. DOI: 10.1108/09513579710367485

Elnaby, H.R., R.W. Epps and A.A. Said, 2003. The impact of environmental factors on accounting development: An Egyptian longitudinal study. Critical Perspectives Account., 14: 273-292.

Freedman, M. and A.J. Stagliano, 2008. Environmental disclosures: electric utilities and phase 2 of the clean air act. Critical Perspectives Account., 19: 466-486. DOI: 10.1016/j.cpa.2007.01.006

Gao, S.S., S. Heravi and J.Z. Xiao, 2005. Determinants of corporate social and environmental reporting in Hong Kong: A research note. Account. Forum, 29: 233-242. DOI: 10.1016/j.accfor.2005.01.002

Gonzalez-Benito, J. and O. Gonzalez-Benito, 2006. A review of determinant factors of environmental proactivity. Bus. Strategy Environ., 15: 87-102. DOI: $10.1002 /$ bse.450

Gray, R., M. Javad, D.Power and D. Sinclair, 2001. Social and environmental disclosure and corporate characteristics: A research note and extension. J. Bus. Finance Account., 28: 327-356. DOI: 10.1111/1468-5957.00376

Halme, M. and H. Morten, 1997. The influence of corporate governance, industry and country factors on environmental reporting. Scandinavian J. Manage., 13: 137-157. DOI: 10.1016/S09565221(97)00002-X

Hassan, O.A.G., G. Giorgioni and P. Romilly, 2006. The extent of financial disclosure and its determinants in an emerging capital market the case of Egypt. Account. Auditing Evaluation, 3: 41-67. DOI: 10.1504/06.10102

Hossain, M., K. Islam and J. Andrew, 2006. Corporate social and environmental disclosure in developing countries: Evidence from Bangladesh. University of Wollongong.

Ince, D., 1998. Corporate, Social and Environmental Reporting (CSER): An Application of Stakeholder Theory. 1st Edn., University of Exeter.

Ingram, R., 1978. An investigation of the information content of (certain) social responsibility disclosures. J. Account. Res., 16: 270-285.

Islam, S., A. Hosen and M. Islam, 2005. An examination of corporate environmental disclosure by the Bangladeshi public limited companies. Pak. J. Soc. Sci., 3: 1095-1102.

Jangou, T., C. Joseph and N. Madi, 2007. The current state of corporate social responsibility among industrial companies in Malaysia. Social Responsibility J., 3: 9-18. DOI: 10.1108/17471110710835536

Marston, C.L. and P.J. Shrives, 1991. The use of disclosure indices in accounting research: A review article. Br. Account. Rev., 23: 195-210. DOI: 10.1016/0890-8389(91)90080-L
Mashat, A., 2005. Corporate Social Responsibility Disclosure and Accountability. Ph.D. Thesis, The Manchester Metropolitan University.

Mckinnon, J.L. and L. Dalimunthe, 1993. Voluntary disclosure of segment information by Australian diversified companies. Account. Finan., 33: 33-50. DOI: 10.1111/j.1467-629X.1993.tb00192.x

Medley, P., 1997. Environmental accounting - what does it mean to professional accountants? Account. Auditing Account. J., 10: 594-600. DOI: 10.1108/09513579710180833

Moneva, J.M. and F. Llena, 2000. Environmental disclosures in the annual reports of large companies in Spain. Eur. Account. Rev., 9: 7-29.

Neuendorf, K.A., 2002. The Content Analysis Guidebook. 1st Edn., Sage Publications, London, ISBN-10: 0761919775 pp: 301.

Owusu-Ansah, S., 1998. The impact of corporate attribites on the extent of mandatory disclosure and reporting by listed companies in Zimbabwe. Int. J. Account., 33: 605-631. DOI: 10.1016/S00207063(98)90015-2

Perera, M.H.B. and M.R. Mathews, 1990. The cultural relativity of accounting and international patterns of social accounting. Advances Int. Account., 3: 215-251.

Saida, D., 2009. Contribution on the analysis of the environmental disclosure: A comparative study of American and European multinationals. Soc. Responsibility J., 5: 83-93. DOI: 10.1108/17471110910940023

Solomon, A. and L. Lewis, 2002. Incentives and disincentives for corporate environmental disclosure. Bus. Strategy Environ., 11: 154-169. DOI: $10.1002 /$ bse. 328

Stanko, B., E. Brogan, E. Alexander and J. Chay, 2006. Environmental accounting. Bus. Econ. Rev., 52: 21-27.

Stevens, W.W.K., 1991. The auditing profession and the "Valdez Principles". Manage. Auditing J. DOI: $10.1108 / 02686909110140823$

Tsang, E.W.K., 1998. A longitudinal study of corporate social reporting in Singapore: The case of the banking, food and beverages and hotel industries. Account. Auditing Account. J., 11: 624-635.

Uwalomwa, U., 2011. An examination of the relationship between management ownership and corporate social responsibility disclosure: A study of selected firms in Nigeria. Res. J. Finan. Account.

Wang, H., J. Bi, D. Wheeler, J. Wang and D. Cao et al., 2004. Environmental performance rating and disclosure: China's Green Watch program. J. Environ. Manage., 71: 123-133. PMID: 15135947

Zarzeski, M.T., 1996. Spontaneous harmonization effects of culture and market forces on accounting disclosures practices. Account. Horizons.

Zubek, F., 2008. An investigation into human resource disclosure. Ph.D. Thesis, Liverpool John Moores University. 